\title{
Phytochemical Screening and Antimicrobial Analysis of Fadogia andersonii Robyn Plant Extract
}

\author{
*NZEAKO, J; NDUKWE, GI; HABILA, JD; OLUWABUKOLA, EA; AND \\ OWOICHO, I
}

Department of Chemistry, Ahmadu Bello University Zaria, Kaduna State Nigeria.
*Corresponding Author Email: joyfullnzeakor@gmail.com; Tel: +2348167625592

\begin{abstract}
Medicinal plants extracts are now generally considered as effective medicines that play a major role in modern pharmacy. The plant Fadogia andersonii belonging to the Family Rubiaceae, which is used in ethno-medicine was studied. Preliminary phytochemical analyses of the whole plant revealed the presence of the following metabolites: Saponins, terpenes, steroids, flavonoids, tannins, alkaloids, cardiac glycosides and carbohydrates. Anthraquinones was found to be absent. Antimicrobial screening of the methanol plant's extract carried out (in vitro) on Staphylococcus aureus, Escherichia coli, Salmonella typhi, Pseudomonas aeruginosa, Bacillus cereus, Klebsiella pneumonia, Streptococcus pneumoniae, Streptococcus pyogenes, Candida albican and Aspergillus flavus showed that the extract has activity on the tested microorganisms. However, it showed no inhibitory effect against Escherichia coli. The extract was found to inhibit the growth of $S$. aureus, B. cereus, $S$. pyogenes and $C$. albican at $25 \mathrm{mg} / \mathrm{ml}$ with a corresponding $\mathrm{MBC}$ at $50 \mathrm{mg} / \mathrm{ml} . S$. typhi and $S$. pneumonia were inhibited at $50 \mathrm{mg} / \mathrm{ml}$ with a corresponding $\mathrm{MBC}$ at $100 \mathrm{mg} / \mathrm{ml}$. It also inhibited the growth of $P$. aeruginosa, K. pneumonia and A. flavus at $100 \mathrm{mg} / \mathrm{ml}$ with a corresponding MBC at $200 \mathrm{mg} / \mathrm{ml}$. The observed antimicrobial effects were believed to be due to the presence of active principles which were detected in the phytochemical screening.
\end{abstract}

DOI: https://dx.doi.org/10.4314/jasem.v25i2.13

Copyright: Copyright $(2021$ Nzeako et al. This is an open access article distributed under the Creative Commons Attribution License (CCL), which permits unrestricted use, distribution, and reproduction in any medium, provided the original work is properly cited.

Dates: Received: 12 December 2020; Revised: 26 January 2021; Accepted: 12 February 2021

Keywords: Phytochemicals, Antimicrobials, Fadogia andersonii Robyn.

Medicinal plants have played essential and exceptional roles since early century in the treatment of several diseases globally. Most Africans still depend on traditional medicine/ethnomedicine of these plants for their medical care because they are considered safer, cheaper, more effective and culturally reliable (Abdulmumeen et al., 2011). The medicinal value of these plants lies in some chemical substances that produce a definite physiological action on the human body. The most important of these bioactive constituents of plants are alkaloids, tannins, flavonoids, saponins and phenolic compounds (Ndukwe et al., 2011). It has been anticipated that secondary plant metabolites (phytochemicals) with good antibacterial activity will be used for the treatment of bacterial infections. This is because, according to Arora and Keur (1999), the success story of chemotherapy lies in the continuous search of new drugs to counter the challenges posed by resistant strains of microorganisms.

Fadogia agrestis, is one of several plants commonly used in the management of erectile dysfunction (Irvine, 1961). Phytochemical screening of the aqueous extract of Fadogia agrestis stem showed the presence of alkaloids and saponins, while anthraquinones and flavonoids are present in a small amount. All other phytochemicals analyzed were not detected (Yakubu et al., 2005). Fadogia erythroophloea (K. Schum \& K. Krause) Hutch. \& Dalziel leaves and fruits are used as antidotes (venomous stings, bites, arrow poison, etc.), emetics, anti-malaria, vermifuge and for childhood fever. The Root is equally used as medicine for diarrhoea, dysentery, colitis and constipation. The stem bark is used as vermifuge. The phytochemical screening of the stem bark extract of the plant revealed the presence of glycosides, alkaloids, saponins, flavonoids, and tannins (Michel, 2004). Fadogia andersonii is a plant that belongs to the genus family of Rubiaceae with evergreen leaves; they grow in a humid climatic environment (Suleiman et al., 2014). It is characterized with erect under shrub 1-2ft height with several stems arising from a woody root stock; flower greenish yellow, fruits yellow, in savannah woody land. It has a branchlets glabrous and it leaves are paired or in threes, oblanceolate $4-5 \mathrm{~cm}$ long, about $1.5 \mathrm{~cm}$ broad, closely venose beneath; flowers few in very shortly pedunculate cymes; calyx-lobes ovate; 
corolla $1 \mathrm{~cm}$ long with acuminate lobes. Fadogia andersonii was found in Ghana where it was first discovered and named by Volta R. Anderson in July 1967 and in Samaru, Zaria Nigeria by Adams in 1982 (Hutchinson et al., 1963). The traditional Hausa people believe that the consumption of Fadogia andersonii, natively called Gagayi in Hausa language can enhance fertility in males. They also believe that taking Fadogia andersonii can stimulate erection in males and enhance sexual performance of males that are impotent. Fadogia andersonii is a popular African medicinal plant, which has long been used in Africa in treatment of diseases including amoebic dysentery (Suleiman et al., 2014). The aim of this research is to justify or otherwise the claims of the ethno-medicinal importance of Fadogia andersonii plant extract.

\section{MATERIALS AND METHODS}

Sample Collection: The plant materials were collected from the bushes around Kudungi village, Zaria, Kaduna State Nigeria in the month of December 2018. It was authenticated by a taxonomist, Mr U.S. Gallah with specimen voucher number No. 7231 at the Herbarium unit of the Department of Biological Sciences, Kaduna State University, Nigeria. The whole plant was air-dried for 21 days and crushed to coarse powder using a wooden mortar and pestle and kept in a polythene bag until required for use.

Preparation of Plant Extract: The dried powdered plant was extracted exhaustively with methanol by cold maceration. The extract was then concentrated invacuo using a rotatory evaporator and the crude extract (residue) dried under vacuum as described by Handa et al., 2008.

Phytochemical Screening: The plant extract was subjected to preliminary phytochemical screening using standard methods.

Test for saponins (Frothing Test): About $0.5 \mathrm{~g}$ of the extract was shaken with water in a test tube followed by warming on a water bath. Frothing persisted on warming which indicated the presence of saponins (Sofowora, 2008).

Test for Triterpenes (Lieberman-Buchard Test): A small portion of the extract was dissolved in chlorofoam and filtered. Equal volume of acetic anhydride was added to the filterate, followed by concentrated sulphuric acid down the side of the test tube. Brown ring at the inter-phase was observed except in methanol extract which indicated the presence of steroids/ triterpenes (Evans, 2009).
Test for Steroids (Salkowski Test): A small quantity of the extract was dissolved in $1 \mathrm{ml}$ chloroform, filtered and to it $1 \mathrm{ml}$ of concentrated sulphuric acid was added down the side of the test tube. Formation of red ring at the interphase was observed except in methanol extract which indicated the presence of sterols (Sofowora, 2008).

Test for Flavonoids (Sodium hydroxide Test): $0.5 \mathrm{~g}$ of the extract were dissolved in water and filtered; $2 \mathrm{ml}$ of $10 \%$ aqueous sodium hydroxide solution was added. The solution turned yellow, a change in colour from yellow to colourless on addition of dilute hydrochloric acid was also observed. This indicated the presence of flavonoids (Evans, 2009).

Test for Tannins (Ferric chloride Test): $0.5 \mathrm{~g}$ of the extracts were stirred with $10 \mathrm{ml}$ distilled water and filtered. Two drops of $1 \%$ Ferric chloride solution were added to $2 \mathrm{ml}$ of the filtrate. Formation of a blueback precipitate was observed except in n-hexane extract. This indicated the presence of tannins (Evans, 2009).

Test for Alkaloids: About 1.0g of the extracts were stirred with $20 \mathrm{ml}$ of $1 \%$ aqueous hydrochloric acid on a water bath and filtered. The filtrate was basified with concentrated $\mathrm{NH}_{4} \mathrm{OH}$ and extracted with choroform. The chlorofoam layer was extracted further with $20 \mathrm{ml}$ of $1 \% \mathrm{HCl}$. The aqueous layer was divided into four portions for the following tests: To the first portion, $1 \mathrm{ml}$ of freshly prepared Dragendorff's reagent was added drop-wise and observed. Rose red to brownish precipitates was formed except in n-hexane extract. To the second $1 \mathrm{ml}$ of Mayer's reagent was added dropwise and observed. Cream colour precipitate was formed in all the extracts. To the third, $1 \mathrm{ml}$ of Wagner's reagent was added, a reddish-brown precipitate was observed in all the extracts (Evans, 2009).

Test for Anthraquinones (Borntrager's Test): The extracts were shaken with $10 \mathrm{ml}$ of benzene and filtered followed by $5 \mathrm{ml}$ of $10 \%$ ammonia solution added to the filtrate. The mixture was shaken gently. No pink red colour in the lower part of the aqueous layer was formed. This indicated the absence of free anthraquinones in the extracts (Evans, 2009).

Test for Cardiac Glycosides (Keller-Killianni Test): About $0.5 \mathrm{~g}$ of the extract was dissolved in $2 \mathrm{ml}$ of glacial acetic acid containing one drop of ferric chloride solution. This was then under layered with $1 \mathrm{ml}$ of concentrated sulphuric acid. A brown ring was obtained at the interphase. This indicated the presence 
of a deoxy sugars characteristic of cardenolides (Evans, 2009).

Test for Carbohydrate (Molisch Test): To a small portion of the extract in test tube, few drops of Molish reagent were added and concentrated sulphuric acid was added down the side of the test tube to form a lower layer. A reddish coloured ring was observed at the interphase which indicated presence of carbohydrates (Evans, 2009).

Antimicrobial analysis: the test organisms: The microorganisms tested were obtained from the Department of Medical Microbiology lab, Ahmadu Bello University Teaching Hospital (ABUTH) Shika, Zaria. All the isolates were checked for purity and maintained in a slant of Mueller Hinton and Potato dextrose agar for bacteria and fungi respectively.

Determination of Inhibitory Activity (Sensitivity Test) of the Extract: The agar well diffusion method was used (Nostro et al., 2000). The standardized inucula of both the bacterial and fungal isolate were streaked on sterilized Mueller Hinton and Potato dextrose agar plates respectively with the aid of a sterile swab sticks. Five wells were punched on each inoculated agar plate with a sterile cork borer. The well was properly labeled according to different concentrations of the extract prepared by serial dilution which were 400, 200, 100, 50 and $25 \mathrm{mg} / \mathrm{ml}$ respectively. Each well was filled up with approximately $0.2 \mathrm{ml}$ of the extract.

The inoculated plates with the extract were allowed to stay on the bench for about one hour and this was to enable the extract to diffuse into the agar. The plates were then incubated at $37^{\circ} \mathrm{C}$ for 24 hours (plates of Mueller Hinton agar) while the plates of potato dextrose agar were incubated at room temperature for about 3-5 days. At the end of incubation periods, the plates were observed for any evidence of inhibition of the microorganism which will appear as a clear zone that was completely devoid of growth around the wells (zone of inhibition). The diameters of the zones were measured using a pair of dividers and read off from transparent ruler calibrated in millimeter and the results were recorded.

Determination of Minimum Inhibitory Concentration $(M I C)$ : The minimum inhibitory concentrations of the extracts were determined using the tube dilution method as outlined by the National Committee for Clinical Laboratory Standards (NCCLS, 2000). The lowest concentration of the extract showing inhibition for each organism when the extract was tested during sensitivity test was serially diluted in the test tubes containing Mueller Hinton broth. The standardized organisms were inoculated into each tube containing the broth and extract. The inoculated tubes were then incubated at $37^{\circ} \mathrm{C}$ for 24 hours. At the end of the incubation period, the tubes were examined/ observed for the presence or absence of growth using turbidity as a criterion. The lowest concentration in the series without visible sign of growth (turbidity) was considered to be the minimum inhibitory concentration (MIC). The result was also recorded.

Determination of Minimum Bactericidal and Fungicidal Concentrations (MBC/MFC): The minimum bactericidal concentration of the extract was determined as outlined by the NCCLS (2000). The result from the minimum inhibitory concentration was used to determine the minimum bactericidal concentration of the extract.

A sterilized wire loop was dipped into the test tube(s) that did not show turbidity (clear) in the MIC test and a loopful was taken and streaked on sterile nutrient agar plates. The plates were incubated at $37^{\circ} \mathrm{C}$ for 18 24 hours and 48 hours for bacteria and fungi respectively. At the end of incubation period, the plates were examined/ observed for the presence or absence of growths. This is to determine whether the antimicrobial effect of the extract is bacteriostatic or bacteriocidal.

\section{RESULTS AND DISCUSSION}

Phytochemical Screening: The qualitative phytochemical analysis of Fadogia andersonii crude plant extract revealed the presence of saponins, terpenes, steroids, flavonoids, tanins, alkaloids, cardiac glycosides and carbohydrates. Anthraquinones were absent in the crude plant sample. The results are shown in Table 1.

\begin{tabular}{ll} 
Table 1: Phytochemical Analysis of Fadogial andersonii \\
\hline Phytochemicals & Fadogial andersonii \\
\hline Saponins & + \\
Terpenes & + \\
Steroids & + \\
Flavonoids & + \\
Tanins & + \\
Alkaloids & + \\
Cardiac glycosides & + \\
Carbohydrates & + \\
Anthraquinones & - \\
\hline \multicolumn{2}{c}{ Key: $+=$ Present, - = Absent }
\end{tabular}

Antimicrobial Analysis: The results of the antibacterial activity tests, expressed in terms of diameter of zones of inhibition, Minimum Inhibitory Concentration (MIC), Minimum Bactericidal Concentration (MBC) of the crude extracts on the test organisms are summarized in Tables 2, 3 and 4. 
Phytochemical Screening and Antimicrobial Analysis......

Table 2: Inhibition Zone (mm) of the Crude Extract

\begin{tabular}{|c|c|c|c|c|c|c|c|}
\hline \multirow[t]{2}{*}{ Test Organisms } & \multicolumn{5}{|c|}{ Concentration of the Extract in $\mathrm{mg} / \mathrm{ml}$} & \multicolumn{2}{|l|}{ Control } \\
\hline & 400 & 200 & 100 & 50 & 25 & CPX $10 \mu \mathrm{g} / \mathrm{ml}$ & FLU $10 \mu \mathrm{g} / \mathrm{ml}$ \\
\hline Staphylococcus aureus & 25 & 22 & 20 & 17 & 14 & 35 & - \\
\hline Escherichia coli & 00 & 00 & 00 & 00 & 00 & 32 & - \\
\hline Salmonella typhi & 23 & 20 & 19 & 16 & 14 & 30 & - \\
\hline Pseudomonas aeruginosa & 19 & 16 & 14 & 11 & 00 & 47 & - \\
\hline Bacillus cereus & 27 & 24 & 21 & 18 & 16 & 32 & - \\
\hline Klebsiella pneumonia & 20 & 17 & 14 & 11 & 00 & 37 & - \\
\hline Streptococcus pneumoniae & 22 & 19 & 17 & 13 & 10 & 45 & - \\
\hline Streptococcus pyogenes & 26 & 23 & 19 & 17 & 13 & 34 & - \\
\hline Candida albicans & 27 & 24 & 21 & 18 & 15 & - & 33 \\
\hline Aspergillus flavus & 17 & 14 & 11 & 00 & 00 & - & 25 \\
\hline
\end{tabular}

Table 3: Minimum Inhibitory Concentration (MIC) of the Crude Extract

\begin{tabular}{|c|c|c|c|c|c|}
\hline \multirow[t]{2}{*}{ Test Organisms } & \multicolumn{5}{|c|}{ Concentration of the Extract in $\mathrm{mg} / \mathrm{ml}$} \\
\hline & 400 & 200 & 100 & 50 & 25 \\
\hline Staphylococcus aureus & - & - & - & - & + \\
\hline Escherichia coli & ND & ND & ND & ND & ND \\
\hline Salmonella typhi & - & - & - & + & ++ \\
\hline Pseudomonas aeruginosa & - & - & + & ++ & +++ \\
\hline Bacillus cereus & - & - & - & - & + \\
\hline Klebsiella pneumoniae & - & - & + & ++ & +++ \\
\hline Streptococcus pneumoniae & - & - & - & + & ++ \\
\hline Streptococcus pyogenes & - & - & - & - & + \\
\hline Candida albicans & - & - & - & - & + \\
\hline Aspergillus flavus & - & - & + & ++ & +++ \\
\hline
\end{tabular}

Keys: ND= Not Determine $;-=$ No turbidity $;+=$ mild turbidity $;++=$ Moderate turbidity $;+++=$ High turbidity.

Table 4: Minimum Bactericidal/Fungicidal Concentration (MBC/MFC) of the Crude Extract

\begin{tabular}{llllll}
\hline Test Organisms & \multicolumn{6}{c}{ Concentration of the Extract $(\mathrm{mg} / \mathrm{ml})$} \\
\cline { 2 - 6 } & $\mathbf{4 0 0}$ & $\mathbf{2 0 0}$ & $\mathbf{1 0 0}$ & $\mathbf{5 0}$ & $\mathbf{2 5}$ \\
\hline Staphylococcus aureus & - & - & - & + & ++ \\
Escherichia coli & ND & ND & ND & ND & ND \\
Salmonella typhi & - & - & + & ++ & ++ \\
Pseudomonas aeruginosa & - & + & ++ & +++ & ++++ \\
Bacillus cereus & - & - & - & + & ++ \\
Kl ebsiella pneumoniae & - & + & ++ & +++ & ++++ \\
Streptococcus pneumonia & - & - & + & ++ & +++ \\
Streptococcus pyogenes & - & - & - & + & ++ \\
Candida albicans & - & - & - & + & ++ \\
Aspergillus flavus & & + & ++ & +++ & ++++
\end{tabular}

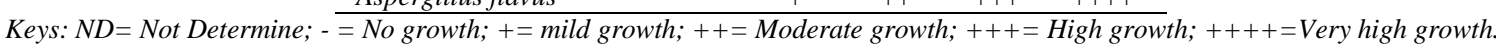

The qualitative phytochemical analysis of Fadogia andersonii whole plant extract revealed the presence of saponins, terpenes, steroids, flavonoids, tanins, alkaloids, cardiac glycosides and carbohydrates while anthraquinones was found to be absent (Table 1). This finding is similar to the result reported on stem bark extract of Fadogia erythrophloea by Sulaiman et al., (2017). The presence of these metabolites which has various pharmacological uses necessitates an in-depth study of the plant extract. Flavonoids are known to be antioxidant in action which prevents the oxidative damage to cells. It possesses the ability to retard the growth of tumors and lowers risk of developing heart disease. It has equally been reported to have strong anticancer and anti-activity (Okwu and Okwu 2004). Alkaloids have anti-malarial, antifungal and antimicrobial activities when used as herbal medicine. Also, tannins in plant are used in the treatment of ulcers, wound and burns. They also possess antioxidant and antimicrobial properties (Okoli et al., 2015). Saponins and tannis have been reported to be able to prevent and stop bleeding from damage vessels by precipitating protein to form vascular plugs hence are said to possess haemostatic activity in plant (Okoli et al., 2007). The results of the antimicrobial studies showed that the extract had remarkable activity at 400 $\mathrm{mg} / \mathrm{ml}$ against eight of the nine microorganisms tested with zones of inhibition between 17 to $27 \mathrm{~mm}$. It could not inhibit the growth of Escherichia coli (Table 2). MIC and MBC studies showed that the extract was found to inhibit the growth of $S$. aureus, B. cereus, $S$. pyogenes and $C$. albicans at $25 \mathrm{mg} / \mathrm{ml}$ with a corresponding $\mathrm{MBC}$ at $50 \mathrm{mg} / \mathrm{ml}$. S. typhi and $S$. pneumonia were inhibited at $50 \mathrm{mg} / \mathrm{ml}$ with a corresponding $\mathrm{MBC}$ at $100 \mathrm{mg} / \mathrm{ml}$. It also inhibited the growth of $P$. aeruginosa, A. flavus and $K$. pneumonia 
at $100 \mathrm{mg} / \mathrm{ml}$ with a corresponding respective $\mathrm{MBCs}$ at $200 \mathrm{mg} / \mathrm{ml}$.

Conclusion: The findings from this research work justify the ethnomedicinal use of the plant material for the treatment of microbial infections. The result showed that the Fadogia andersonii plant extract possesses a broad spectrum of anti-microbial activity against many of the microorganisms implicated in the pathogenesis of human infections. The broad spectrum of inhibition observed may be attributed to the various bioactive constituents present in it as recorded in the phytochemical screening.

\section{REFERENCES}

Abdulmumeen, AH; Olapeju, OA; Azeezat, AY; Taibat, OS; Motunrayo, RD; Ruth, OS (2011). Baleria opaca: phytochemical evaluation, antibacterial and antifungal properties. Adv. Appl. Sci. Res. 2 (5): 624-631.

Arora, D; Keur, J (1999): Antimicrobial activity of spices. Inter. J. Antimicrobial agents. 12: $257-$ 262.

Evans, WC (2009). 'Trease and Evans' Pharmacognosy. Fourteenth Edition. W. B. Saunders Company Ltd. London. pp. 119-120; 194-227\&343.

Handa, SS; khanuja SPS; Longo, G; Rakesh DD (2008). Extraction Technology for medicinal and Aromatic plants. Industrial development organization and international centre for science and Technology United nation, Italy. pp. 66.

Hutchison J; LLD; FRS; VMH; FLS (1963). Rubiaceae family. In Text book of Flora of West Tropical Africa $2^{\text {nd }}$ ed. Edited by F.N. Hepper, B.SC., F.L.S 1980. Published by Crown Agent Botany for Oversea Government and Administrations Millibank London S.W.I; 117 178.

Irvine, FR (1961). Woody plants of Ghana. London: Oxford University Press; pp 878.

Michel, A (2004). Trees, Shrubs \& Lianas of West Africa Dry Zones. CIRAD $1^{\text {st }}$ ed. Retrieved from http://www.quae.com/en/r367-trees-shrub-andlianas-of-west-african-dry-zones.html.

National Committee for Clinical Laboratory Standards (2000). Methods for dilution antimicrobial susceptibility tests for bacteria that grow aerobically; Approved Standard Fifth Edition.
NCCLS Document M7-A5, NCCLS: Wayne, PA, USA.

Ndukwe, GI; Bello, IA; Audu, OT; Habila, JD (2011). A Bioactive Flavonoid from Pavette crisspes. Organic and Medicinal Chemistry Letters, 1:14. Retrieved from http://www.orgmedchemlett.com/content/1/1/14.

Nostro, A; Germano, MP; D’Angelo, Marino, A; Cannatelli MA (2000). Xtraction Methods and Bioautography for Evaluation of Medicinal Plant Antimicrobial activity. Letter of Applied Microbiology, 30: 379-384.

Okoli, RI; Turay, AA; Mensah, JK (2015). The Phytochemical Analysis and Antibacterial Effects of Stem Bark Extracts of Brachystegia Eurycoma Harms. Inter. J. Herbs and Pharmacol. Res. 4(2): $10-16$

Okoli, CO; Akah, PA; Okoli, AS (2007). Potentials of leaves of Aspilia africana (Compositae) in wound care: An experimental evaluation. BMC Comp. Alt. Med. 7:24-30.

Okwu, DE; Okwu, ME (2004). Chemical composition of Spondias mombin Linn plant parts. J. Sustain. Agric. Environ. 6(2):140-147

Sofoworo, LA (2008). Medicinal plants and Traditional Medicine in Africa. $2^{\text {nd }}$ Edn., Spectrum Books Ltd., Ibadan, Nigeria, ISBN: 9789780298814, Pages: 289.

Sulaiman, AI; Ndukwe, GI (2017). Phytochemical and Antibacterial Susceptibility Studies of the Stem bark Extract of Fadogia erythrophloea (K. Schum. And K. Krause) Hutch. \& Dalziel. Bayero J. Pure and App. Sci. 10(1): $629-633$.

Suleiman, I; Mabroukb, MA; Alhassana, AW (2014). Effect of aqueous root extract of Fadogia andersonii on sperm count and motility in adult male Wistar rats. Annals Biol. Sci. 2 (4):33-36.

Yakubu, MT; Akanji, MA; Oladiji, AT (2005). Aphrodisiac potentials of the aqueous extract of Fadogia agrestis (Schweinf. Ex Hiern) stem in male albino rats. Asian J. Androl; 7 (4): 399-404. 